\title{
PENGEMBANGAN MODUL AJAR MATA KULIAH PERTUMBUHAN DAN PERKEMBANGAN MOTORIK BERBASIS PEMBELAJARAN INKLUSI
}

\author{
Fitriana Puspa Hidasari, Lidya Natalia, Yoga Pramana \\ Fakultas Keguruan dan Ilmu Pendidikan \\ Universitas Tanjungpura \\ e-mail: fitriana.puspa@fkip.untan.ac.id
}

\begin{abstract}
The study aims to develop teaching modules for Growth and Motor Development Subject. Research urgency is based on the needs analysis of subject that required guidance in the form of teaching madules that are not yet available in order to help optimally the learning process. The research was conducted using $R \& D$ method which is divided into two stage, there are predevelopment stage and development stage. The pre-development stage consists of preliminary studies, products drafting, and validating product drafts. The development stage consists of revisions to product drafts, limited-scale test and large-scale test. Expert validation involves one expert used focus group discussion techniques. In the limited-scale and large-scale test conducted to see the content aspect and the format of the teaching module qualitatively well received by the students and teaching module has been feasible to be used in the lectures of growth and motor development with 34 students as subjects research. In operational tes used experimental method with 34 students. The instruments used in data collection at the pre-development stage use field notes, validation sheets, and acceptance test sheets, while in the development stage using a questionnaire measure the usefulness of the teaching module. Data analysis techniques used are qualitative descriptive and qualitative analysis techniques. The result of the teaching module development consists of six materials, there are: (1) cover, (2) introduction, (3) table of contents, (4) the purpose of teaching module, (5) the content of the teaching module, (6) chapter summary, and (7) formative questions. Based on the assessment of the validator on the substance of the content $92 \%$ is included in the very well category and the writing format is 92\% considered very well category. Overall assessment of the esperts obtained 92\% value include in the very well category. The next stage is the acceptance test that is assessed by the results of $87 \%$ of students receive the existence of the teaching module. The results of a limited scale test showed that the substantive aspects are categorised well and the writing format is categorized well whereas in large-scale it shows the substantive aspect and writing format categorized well. The result of the study states that the teaching module is worth using. The large-scale test results show that the developed teaching module is acceptable and feasible using the difference between the mean value of pretest 62 and posttest 75. Based on the research result, it can be concluded that the teaching module is acceptable and feasible to be used in Growth and Motor Development lectures.
\end{abstract}

Keywords : teaching module, inclusion, growth and motor development.

\begin{abstract}
ABSTRAK
Penelitian bertujuan mengembangkan modul ajar untuk mata kuliah pertumbuhan dan perkembangan motorik. Urgensi penelitian didasarkan pada analisis kebutuhan mata kuliah yang memerlukan panduan berupa modul ajar yang belum tersedia agar dapat membantu optimalnya proses pembelajaran. Penelitian dilakukan menggunakan metode penelitian dan pengembangan (R\&D) yang terbagi dalam dua tahapan yaitu tahap pra-pengembangan dan tahap pengembangan. Tahap pra pengembangan terdiri dari studi pendahuluan, penyusunan draf produk dan validasi draf produk. Tahap pengembangan terdiri dari revisi draft produk, ujicoba skala terbatas dan ujicoba skala meluas. Validasi ahli dilakukan melibatkan satu orang ahli dengan menggunakan teknik focus group discussion (FGD).
\end{abstract}


Pada uji skala terbatas dan luas dilakukan untuk melihat aspek subtansi isi dan dan format modul ajar secara kualitatif diterima dengan baik oleh mahasiswa dan modul ajar telah layak digunakan pada proses perkuliahan mata kuliah pertumbuhan dan perkembangan motorik dengan subjek coba 34 mahasiswa. Pada uji operasional menggunakan metode eksperimen dengan subjek coba 34 mahasiswa. Instrumen yang digunakan dalam pengumpulan data pada tahap pra-pengembangan menggunakan catatan lapangan, lembar validasi, dan lembar uji keberterimaan, sedangkan pada tahap pengembangan menggunakan angket mengukur tingkat kebermanfaatan modul ajar. Teknik analisis data yang digunakan adalah teknik analisis deskriptif kualitatif dan analisis kuantitatif (statistik). Hasil dari pengembangan modul ajar terdiri dari enam materi didalamnya dengan sebagai berikut: (1) cover, (2) kata pengantar, (3) daftar isi, (4) tujuan modul ajar, (5) isi modul ajar, (6) rangkumam bab dan (7) soal-soal formatif. Berdasarkan penilaian dari validator terhadap substansi isi materi 92\% termasuk dalam kategori sangat baik dan format penulisan modul ajar dinilai 92\% termasuk kategori sangat baik. Secara keseluruhan penilaian dari para ahli diperoleh nilai $92 \%$ termasuk dalam kategori sangat baik. Tahapan selanjutnya adalah uji keberterimaan yang dinilai dengan hasil $87 \%$ mahasiswa menerima adanya modul ajar mata kuliah. Hasil ujicoba skala terbatas menunjukan secara aspek substantif dikategorikan baik dan format penulisan dikategorikan baik sedangkan pada ujicoba skala luas menunjukan secara aspek substantif dikategori baik dan format penulisan di kategori baik. hasil penelitian menyatakan modul ajar layak digunakan. Hasil uji skala meluas menunjukan modul ajar yang dikembangkan dapat diterima dan layak diunakan yang ditunjukkan degan pebedaan nilai mean pretest 62 dan posttest 75 .

Berdasarkan hasil penelitian dapat disimpulkan modul ajar dapat diterima dan layak digunakan pada mata kuliah Pertumbuhan dan Perkembangan Motorik.

Kata Kunci: Modul Ajar, Inklusi, Pertumbuhan dan Perkembangan Motorik.

\section{PENDAHULUAN}

Masih rendahnya mutu pendidikan

di Indonesia dapat dilihat dari berbagai te-

muan pendidikan dan survei dari lembaga

independen. Dari hasil riset yang dilaku-

kan UNDP (United Nations Development

Programme) yang melakukan riset terha-

dap human development index (HDI) dan

publikasikan pada tahun 2010, terhadap

169 negara menempatkan Indonesia di po-

sisi 108 (UNDP, 2012). Data tersebut ha- rusnya dapat menjadi cerminan agar selu-

ruh pihak dapat meningkatkan mutu pendi-

dikan di Indonesia, setiap elemen harus

ber-kontribusi walau sedikit agar cita-cita

bang-sa dapat terwujud.

Perubahan kurikulum pendidikan

tinggi di Indonesia diawali dengan Peratur-

an Presiden Nomor 8 Tahun 2012, tentang

Kerangka Kurikulum Nasional Indonesia.

PerPres tersebut menuntut adanya

perubah-an sistem di pendidikan tinggi, 
PerPres ter-sebut kemudian diperkuat oleh peraturan Menteri Pendidikan dan Kebudayaan Repu-blik Indonesia Nomor 79 tahun 2013 ten-tang penerapan Kerangka Kurikulum Nasi-onal Indonesia, Pasal 3 Ayat 5 disebutkan bahwa Capaian pembelajaran sebagaimana dimaksud merupakan kemampuan yang di-peroleh melalui internalisasi pengetahuan, sikap, keterampilan, kompetensi, dan aku-mulasi pengalaman kerja.

Perubahan-perubahan tersebut diharapkan dapat meningkatkan mutu dan kualitas dari pendidikan Indonesia khususnya Pendidikan Tinggi. Hal ini tentu berdampak pada proses pembelajaran yang berlangsung, terutama pada aspek pemenuhan tuntutan PerMen Nomor 79 tahun 2013. Untuk menentukan capaian pembela-jaran maka perlu dipetakan kemampuan mahasiswa dalam memahami keluasan dan kedalaman suatu materi mata kuliah me-lalui bahan ajar hal tersebut dapat dides-kripsikan. Bahan ajar yang berupa modul adalah satu dari beberapa komponen yang menentukan tingkat keberhasilan dari sebu-ah pembelajaran karena bahan ajar meru-pakan salah satu sumber belajar utama bagi mahasiswa. Bahan ajar setiap mata kuliah harus dirancang dengan tepat oleh masingmasing dosen pengampu mata kuliah agar dapat ditentukan koridor dan arah pembahasan materi ajar selama satu semester sehingga dapat ditentukan standar kompetensi mahasiswa. Bahan ajar juga harus menggunakan beberapa strategi pendekatan agar menarik bagi mahasiswa dan berbeda dari sumber-sumber belajar lainnya sehingga diperlukan suatu penelitian untuk merancang dan membuat bahan ajar menjadi sumber referensi yang utama dan jelas.

Di Prodi Pendidikan Jasmani Kesehatan dan Rekereasi belum tersedia bahan ajar bagi mahasiswa untuk mata kuliah Pertumbuhan dan Perkembangan Motorik sehingga sumber utama bagi mahasiswa dalam belajar adalah internet. Hal ini cukup menyulitkan karena bahan-bahan sumber internet belum di filter menjadi 
bahan uta-ma kajian dan belum dikemas menjadi sum-ber bahan yang siap pakai bagi mahasiswa. Selain itu, untuk mendukung reakreditasi prodi tahun 2019 diperlukan persiapan umum dan khusus untuk menghadapi pro-ses visitasi agar pencapaian akreditasi dapat ditingkatkan lagi, salah satu item adalah ke-lengkapan bahan ajar di sebuah prodi.

Pada penelitian ini pengembangan bahan ajar didasarkan pada analisis kebutuhan mahasiswa. Terdapat sejumlah alasan mengapa perlu dilakukan pengembangan bahan ajar, yaitu; (1) Ketersediaan bahan sesuai tuntutan kurikulum; (2) Karakteristik sasaran, artinya bahan ajar yang dikem-bangkan

Tabel 1. Capaian Luaran Penelitian

\begin{tabular}{|c|l|l|l|}
\hline No & \multicolumn{1}{|c|}{$\begin{array}{c}\text { Jenis } \\
\text { Luaran }\end{array}$} & \multicolumn{1}{|c|}{ Target } & \multicolumn{1}{c|}{ Capaian } \\
\hline 1 & Modul ajar & Draft & Draft \\
\hline 2 & $\begin{array}{l}\text { Pemakalah } \\
\text { dalam temu } \\
\text { ilmiah } \\
\text { Nasional/ } \\
\text { Internasional }\end{array}$ & Tidak Ada & $\begin{array}{l}\text { Terlaksana pada } \\
\text { IcoTE (Novem- } \\
\text { ber 2017) }\end{array}$ \\
\hline
\end{tabular}

\section{KAJIAN LITERATUR}

Menurut Sugiyono penelitian dan pengembangan atau dalam bahasa Inggris- disesuaikan dengan karakteristik mahasiswa sebagai sasaran, karakteristik tersebut meliputi lingkungan sosial, budaya, geografis maupun tahapan perkembang-annya; (3) Pengembangan bahan ajar juga dapat menjawab atau memecahkan masalah atau kesulitan dalam belajar pada mahasis-wa; (4) Dapat menjadi sumber belajar uta-ma bagi mahasiswa.

\section{Target dan Luaran}

Luaran yang dihasilkan dari penelitian dengan judul "Pengembangan Modul Ajar Mata Kuliah Pertumbuhan dan Perkembangan Motorik Berbasis Pembelajaran Inklusi” tersaji pada tabel 1 . nya Research and Development adalah penelitian yang digunakan untuk menghasilkan produk tertentu, dan menguji keefek-tifan produk tersebut. Kemudian menurut Sukmadinata penelitian dan pengembangan adalah suatu proses atau langkah-langkah untuk mengembangkan suatu produk baru atau menyempurnakan 
produk yang telah ada, yang dapat dipertanggungjawabkan. Sedangkan menurut Gay dalam Asim men-jelaskan penelitian pengembangan adalah suatu usaha untuk mengembangkan suatu produk yang efektif yang digunakan di sekolah, bukan untuk menguji teori. Dwiyogo juga memberikan pendapat bahwa peneli-tian pengembangan merupakan penelitian yang berorientasi untuk menghasilkan atau mengembangkan produk.

Pembelajaran inklusi mengenalkan pembelajaran dengan berbagai tugas yang berbeda-beda tingkat kesulitannya. Dalam gaya ini peserta didik didorong untuk menentukan tingkat penampilannya. Pernyata-an tersebut senada dengan Mosston, pem-belajaran inklusi adalah pedoman mengajar yang dipakai oleh dosen menyajikan materi pembelajaran secara keseluruhan secara rinci yang memaparkan tingkat kesulit-annya. Terdapat juga tujuan dari pembela-jaran inklusi adalah (1) melibatkan semua peserta didik, (2) penyesuaian terhadap per-bedaan individu, (3) memberikan kesem-patan untuk memulai pada tingkat kemam-puan sendiri, (4) memberikan kesempatan untuk memulai bekerja dengan tugas-tugas yang ringan ke berat, sesuai dengan tingkat kemampuan setiap peserta didik, (6) indivi-dualisasi dimungkinkan, Karena memilih antara alternatif tingkat tugas yang telah disediakan.

Dalam mata kuliah teoretik khususnya pertumbuhan dan perkembangan moto-rik, penerapan pembelajaran inklusi dapat mempermudah peserta didik dengan berba-gai kebebasan menentukan dan memilih tingkat kesulitan materi pembelajaran teo-retik. Penyusunan tingkat kesulitan sangat diperlukan dalam pembelajaran teoretik, Dalam proses belajar, peserta didik diberi kebebasan untuk memilih salah satu dari tingkattingkat kesulitan materi pembela-jaran seperti tersebut di atas pada setiap pertemuan, peserta didik juga diberi kebe- 
basan untuk berpindah mempelajari materi perkuliahan lain dengan cara memberikan check list pada lembaran tugas yang telah disediakan oleh dosen pada pertemuan lain yang penting materi tersebut mudah dikuasai.

\section{METODE PENELITIAN}

Jenis penelitian ini termasuk penelitian pengembangan (Research and Development). Research and Development adalah rangkaian proses atau langkah-langkah dalam rangka mengembangkan suatu produk baru atau memperbaiki produk-produk yang telah ada agar dapat dipertanggungjawabkan (Direktorat Tenaga Kependidikan dan Direktorat Jenderal Peningkatan Mutu Pendidikan dan Tenaga Kependidikan, 2008). Selanjutnya menurut Borg and Gall (1989: 624), educational research and development is a process used to develop and validate educational product. Jadi da-pat dipahami bahwa penelitian pengem-bangan adalah suatu proses kajian yang sis-tematis untuk mengembangkan suatu pro-duk baru atau menyempurnakan produk yang sudah ada dan menguji keefektif-annya. Produk yang dikembangkan/diha-silkan antara lain berupa bahan pelatihan untuk dosen, bahan ajar, dan media pem-belajaran.

Model penelitian dan pengembangan memiliki sepuluh langkah pelaksanaan penelitian (Borg dan Gall, 1983: 775) yaitu: (1) studi pendahuluan dan pengumpulan data (kajian pustaka, pengamatan lapangan, membuat kerangka kerja penelitian), (2) perencanaan (tujuan penelitian, dana, wak-tu, prosedur penelitian, berbagai bentuk partisipasi, (3) mengembangkan produk awal (perencanaan draft awal produk dan validasi), (4) ujicoba awal (mencoba draft produk ke wilayah dan subjek yang terbatas), (5) revisi untuk menyusun produk utama, (6) uji coba lapangan utama (uji coba ke wilayah dan subjek yang lebih luas), (7) revisi untuk menyusun produk operasional, (8) uji coba produk operasional (uji efektif produk), (9) revisi produk final (revisi produk yang efektif), dan (10) 
diseminasi dan implementasi produk hasil pengembangan (tujuannya agar produk yang baru saja dikembangkan dapat dipakai oleh mahasiswa).

Dalam penelitian ini peneliti mengi-kuti langkah-langkah pengembangan pro-duk menggunakan metode pengembangan Borg \& Gall karena fokus penelitian ini adalah pembelajaran, bertujuan untuk menghasilkan produk modul Mata Kuliah Pertumbuhan dan Perkembangan Motorik di Prodi Penjaskesrek FKIP Untan.

Penelitian dilaksanakan di Prodi Penjaskesrek FKIP UNTAN yang beralamat di Jl. Nurul Huda, Kabupaten Kubu Raya, Kalimantan Barat.

Populasi dalam penelitian ini adalah seluruh mahasiswa yang menempuh Mata Kuliah Pertumbuhan dan Perkembangan Motorik Tahun Ajaran 2017-2018. Sampel penelitian menggunakan teknik purpossive yaitu tergantung pada kegiatan yang dilaksanakan. Pada kegiatan uji coba terbatas, sampel yang digunakan sebanyak 30 maha-siswa. Untuk uji coba meluas, sampel yang digunakan seluruh mahasiswa yang me-nempuh mata kuliah Pertumbuhan dan Per-kembangan Motorik Tahun Ajaran 2017-2018.

Pengumpulan data dalam penelitian dan pengembangan dilakukan pada tahap pendahuluan, validasi dan uji coba. Pada tahap tersebut dipilih teknik pengumpulan data tertentu sesuai dengan tujuan masingmasing. Pada studi pendahuluan dipilih teknik kuesioner/angket, observasi, dan do-kumentasi. Selanjutnya tahap validasi digu-nakan lembar validasi. Pada tahap uji coba atau pengembangan, terdapat dua langkah yang berkaitan dengan teknik pengumpulan data, yaitu uji coba terbatas dan uji coba luas.

\section{HASIL PENELITIAN}

Berdasarkan hasil penelitian pengembangan yang dilakukan, diperoleh beberapa hasil dan luaran yang dicapai.

\section{Tahap Prapengembangan:}


1. Telah ditemukan kekurangan rancangan metode pembelajaran yang perangkat pembelajaran pada Mata telah dirumuskan menjadi draf modul ajar Kuliah Per-tumbuhan dan adalah:

Perkembangan Motorik.

2. Didapatkan deskripsi kemampuan analisa berpikir mahasiswa prodi penjas se-mester I.

3. Telah ditemukan deskripsi kurikulum pembelajaran prodi penjas semester I.

4. Telah dirumuskan metode ajar untuk mahasiswa prodi penjas semester I.

5. Telah disusun draf produk modul ajar mata kuliah Pertumbuhan dan Perkembangan Motorik.

\section{Tahap pengembangan:}

Berdasarkan hasil studi literatur, pe-nelitian relevan dan studi lapangan diru-muskan metode pembelajaran yang dikem-bangkan yaitu menggunakan prinsip dari metode pembelajaran inklusi, sebaai dasar penyusunan rancangan metode pembelajar-an inklusi untuk menstimulasi kemauan dan kemampuan berpikir mahasiswa. Adapun hasil
1. Modul ajar memuat anatomi bahan ajar mengacu pada format Fakultas Keguruan dan Ilmu Pendidikan Universitas Tanjungpura,

2. Modul ajar memuat materi-materi yang relevan dengan mata kuliah Pertumbuhan dan Perkembangan Motorik,

3. Modul ajar mata kuliah Pertumbuhan dan Perkembangan Motorik mengguna-kan sumber referensi yang terbarukan,

4. Modul ajar mata kuliah Pertumbuhan dan Perkembangan Motorik disusun berdasarkan materi dasar hingga materi yang kompleks,

5. Modul ajar mata kuliah Pertumbuhan dan perkembangan motorik memuat se-rangkaian contoh soal dalam bentuk studi kasus,

6. Modul ajar mata kuliah Pertumbuhan dan perkembangan motorik memuat se-jumlah tes formatif untuk 
menstimula-si kemampuan berpikir mahasiswa.

\section{Tahap validasi}

Setelah dilakukan validasi oleh ahli dan dilakukan penyempurnaan produk maka dihasilkan modul ajar.

Tabel 2. Hasil Penilaian Draft Modul Ajar

\begin{tabular}{|c|c|c|c|}
\hline \multicolumn{4}{|c|}{ Jumlah } \\
\hline $\begin{array}{c}\text { Unsur } \\
\text { Penilaian }\end{array}$ & $\mathbf{N}$ & $\mathbf{P}$ & Kategori \\
\hline Isi Materi & 7 & $92 \%$ & Sgt baik \\
\hline Format & 7 & $92 \%$ & Sgt baik \\
\hline Jumlah & 14 & $92 \%$ & Sgt baik \\
\hline
\end{tabular}

\section{Tahap uji coba}

Modul ajar diberikan kepada mahasiswa dan digunakan dalam 3 kali pertemu-an perkuliahan. Setelah digunakan bebera-pa kali, mahasiswa diberikan lembar peni-laian uji keberterimaan terhadap produk modul ajar mata kuliah Pertumbuhan dan Perkembangan Motorik. Berikut disajikan hasil dari uji keberterimaan mahasiswa terhadap produk modul ajar yang telah dibuat.

Tabel 3. Hasil Penilaian Modul Ajar

\begin{tabular}{|c|c|c|c|}
\hline \multicolumn{4}{|c|}{ Jumlah } \\
\hline $\begin{array}{c}\text { Unsur } \\
\text { Penilaian }\end{array}$ & $\mathbf{N}$ & $\mathbf{P}$ & Kategori \\
\hline $\begin{array}{l}\text { Produk Modul } \\
\text { Ajar }\end{array}$ & 34 & $87 \%$ & Sgt baik \\
\hline Jumlah & 34 & $87 \%$ & Sgt baik \\
\hline
\end{tabular}

Setelah uji coba dihasilkan modul ajar untuk mata kuliah Pertumbuhan dan Perkembangan Motorik pada skala terbatas secara substansinya tergolong baik dan aspek pelaksanaannya tergolong baik. Pada uji coba luas substansinya tergolong sangat baik dan aspek pelaksanaannya tergolong sangat baik sehingga dihasilkan model yang layak untuk digunakan.

\section{KESIMPULAN DAN SARAN}

Berdasarkan pada hasil penelitian dan pembahasan yang telah dikemukakan, maka dirumuskan beberapa kesimpulan pe-nelitian sebagai berikut:

1. Pengembangan modul ajar disusun ber-dasarkan analisis kebutuhan yang men-desak dan berdasarkan metode pembel-ajaran inklusi, unsur-unsur yang dikem-bangkan dalam modul ajar yaitu prinsip kejelasan substansi 
isi/materi, kelayak-an modul, dan format penulisan yang sesuai dan berlaku di Fakultas Kedo-senan dan Ilmu Pendidikan Universitas Tanjungpura. Materi-materi pembelajaran disusun dari level dasar sampai level kompleks sesuai dengan metode inklusi yang digunakan dan dikemas dalam bentuk modul ajar.

2. Berdasarkan hasil validasi oleh ahli ma-ka dilakukan penyempurnaan dan diha-silkan produk modul ajar untuk mata kuliah pertumbuhan dan perkembangan motorik yang secara substansi isi materi sangat baik dan format penulisan cukup baik.

3. Dihasilkan modul ajar untuk mata kuliah pertumbuhan dan perkembangan motorik pada skala terbatas secara substansi dikategorikan baik dan format modul dikategorikan baik. Pada uji coba luas substansinya dikategorikan sangat baik dan format modul dikategorikan sangat baik sehingga dihasilkan modul yang layak untuk digunakan da- lam perkuliahan. Modul Ajar dapat menstimulasi mahasiswa dan memudahkan mahasiswa dalam pembelajaran.

Berdasarkan kesimpulan hasil penelitian dan pengembangan dan atas keung-gulan yang dimiliki modul ajar untuk mata kuliah Pertumbuhan dan Perkembangan Motorik, disampaikan sejumlah saran seba-gai rekomendasi yaitu:

1. Saran bagi mahasiswa selaku pengguna. Agar implementasi penggunaan mo-dul ajar dapat dilaksanakan pada mata kuliah pertumbuhan dan perkembang-an motorik dengan optimal, maka ada beberapa saran yang dapat diajukan se-bagai rekomendasi untuk mahasiswa sebagai pengguna yaitu:

a. Modul ajar untuk mata kuliah pertumbuhan dan perkembangan moto-rik ini sudah diuji kelayakannya dan bermanfaat untuk diterapkan. Hal ini 
dikarenakan modul yang dikembangkan mengikuti karakteristik mahasiswa dan menggunakan metode ajar inklusi yang telah teruji secara teori. Akan tetapi, dalam pro-ses pelaksanaannya diperlukan sua-tu proses yang terus menerus serta memperbaiki kelemahan yang mun-cul dalam pelaksanaannya agar per-baikan ke depan dapat berjalan se-cara optimal.

b. Modul Ajar untuk mata kuliah pertumbuhan dan perkembangan moto-rik telah teruji dapat diterima maha-siswa sebagai salah satu sumber belajar yang relevan. Modul ajar yang dikembangkan dapat dipakai sebagai alternatif bagi mahasiswa dalam pelaksanakan pembelajaran di kelas. Hal ini menjadikan peser-ta didik harus bersungguh-sungguh dalam melaksanakan proses pembelajaran sesuai dengan prosedur yang telah dibuat sehingga akan mudah dalam melakukan evaluasi proses dan hasil belajar.

2. Saran pada pihak peneliti berikutnya. Penelitian dan pengembangan ini mem-punyai keterbatasan, karena itu dipan-dang perlu adanya saran sebagai reko-mendasi bagi peneliti berikutnya antara lain:

a. Terlepas dari kekurangan yang ada, penelitian tentang pengembangan modul ajar pada mata kuliah pertumbuhan dan perkembangan motorik perlu ditindaklanjuti dengan penelitian-penelitian sejenis yang menjangkau karakteristik mahasiswa yang lebih luas. Dengan demikian, akan diperoleh berbagai varia-si modul ajar dengan metodemeto-de ajar lain yang tertuju pada keba-haruan ilmu pengetahuan.

b. Penelitian dan pengembangan ini dilakukan di Prodi Pendidikan Jasmani Fakultas Kedosenan dan Ilmu Pendidikan Universitas Tanjungpura yang hasilnya menunjukkan 
efek-tif dan layak digunakan sebagai ba-gian dari salah satu sumber belajar relevan bagi mahasiswa yang meng-ambil mata kuliah pertumbuhan dan perkembangan motorik.

\section{DAFTAR PUSTAKA}

Borg and Gall. (1983). Educational research: An indtroduction ( $4^{\text {th }} e d$ ). New York: Longman.
Dwiyogo. (2002). Konsep Penelitian dan Pengembangan, Disajikan Pada Lokakarya Metodologi Penelitian Jurusan Pembelajaran Fakultas Ilmu Keolahragaan Universitas Negeri Malang.

Hurlock, Elizabeth. (1990). Psikologi Pengembangan Suatu Pendekatan Rentang Kehidupan. Jakarta: Erlangga.

Sugiyono. (2008). Metode Penelitian Kuantitatif, Kualitatif dan $R$ \& D. Bandung: Alfabeta.

Sukmadinata. (2005). Metode Penelitian Pendidikan. Bandung: Rosdakarya. 